\title{
Testing Farmers' Perception of Climate Variability: A Case Study from Kirtipur of Kathmandu Valley
}

Jiban Mani Poudel

\begin{abstract}
In the 21st century, global climate change has become a public and political discourse. However, there is still a wide gap between global and local perspectives. The global perspective focuses on climate fluctuations that affect the larger region; and their analysis is based on long-term records over centuries and millennium. By comparison, local peoples' perspectives vary locally, and local analyses are limited to a few days, years, decades and generations only. This paper examines how farmers in Kirtipur of Kathmandu Valley, Nepal, understand climate variability in their surroundings. The researcher has used a cognized model to understand farmers' perception on weather fluctuations and climate change. The researcher has documented several eyewitness accounts of farmers about weather fluctuations which they have been observing in a lifetime. The researcher has also used rainfall data from 1970-2009 to test the accuracy of perceptions. Unlike meteorological analyses, farmers recall and their understanding of climatic variability by weather-crop interaction, and events associating with climatic fluctuations and perceptions are shaped by both physical visibility and cultural frame or belief system.
\end{abstract}

Key words: Farmer's perception, weather, climate change, experience, Nepal

\section{Introduction}

Grom the beginning of the 21st century, climate $\boldsymbol{F}$ change has become a public and political discourse in global context. However, there is still a wide gap between different perspectives such as global and local, natural science and ethno-science, descriptive and interpretive to understand climate variability. The global perspective focuses on climatic change that affects the larger region; and their analyses are based on long-term records like centuries and millennia. By comparison, ethno-perspective interests in local climatic variations and their analyses are limited to a few days, years, decades and generations and sometimes with a single event. ${ }^{1}$ Similarly, natural scientists use meteorological data whereas local people use their own experiences, observation and oral tradition through which they perceive and interpret climate variability in their local surroundings. However, natural scientists still believe that lay people cannot detect climate variability (Kempton, Boaster and Hartley 1997, cited in West and VásquezLeón 2003:233). On the contrary, social scientists like anthropologists consider local people including farmers as primary witnesses of climate variability in the local surroundings. As primary eyewitness of climate variability, "people talk about the recent weather and the weather this is to come, they remember the conditions months ago and anticipate future seasons, and they discuss the weather far in the past as well" (Strauss and Orlove 2003:3).

There are wider differences in epistemological understandings between the descriptive/positivistic approach and the interpretive approach in weather and climate research. The positivistic perspective emphasizes meteorological data and visible objects/facts, whereas an interpretive perspective focuses on insider's perspectives, which are cognized and culturally framed in the given context (West and Vásquez-León 2003:233). The first perspective emphasizes quantitative data and examines trend and pattern of changes over time period. The second is embedded with culture having subjective and contextual meanings (Crate 2008) that cannot be seen by naked human eyes (Orlove, Wiegandt and Luckman 2008:5) and cannot be explained by operational models (Rappaport
1979:97-98). Moreover, it is far from the sphere of descriptive, media headline, political and donor driven perspectives (Roncoli, Crane and Orlove 2009).

The main concern of this paper is with an understanding of how farmers have cognized climate variability in Kathmandu Valley. In this context, this paper will try to answer the following questions:

- How do local farmers understand weather fluctuations and climate change?

- How and what have farmers been experiencing on climate variability?

- What is the nature of relation between local and scientific knowledge?

- What are their coping mechanisms in the present context?

\section{Research Methods}

The farming area of Kirtipur, Nepal was selected as a study site to examine the farmers' perceptions on climate variability. There were some reasons for selecting this site for the present study. First, agriculture of the area was largely depending on seasonal rainfall. Second, the researcher was also observing low precipitation and its impacts on agricultural calendar over a few years. Therefore, it was more suitable to the researcher for better understanding of farmers' perception on climate variability through crop-weather interaction. Despite these reasons, how farmers interpreted the fluctuation of weather and climate pattern is an important research question by itself for social scientists. The researcher frequently visited the field in 2010 and 2011 and talked with 24 elderly farmers and collected their lifetime experiences and eyewitness accounts.

\section{The Settings}

This study was conducted at Khatrichhap in Kirtipur located at the southwestern region. The local people classified the area into three ethno-climatic zones. The southwestern part is wet and moisturized due to its location at the bottom of the hill which is called sim, meaning 
wet-land. There is sufficient water and water sources that are used to irrigate paddy field for plantation in summer. Due to highly moisturized land, paddy plantation is held between first and second weeks in June. Delay in the plantation causes immature and unripe paddy. In winter, the land remains barren.

The middle part of the area is called tar. It is drier than two other ecological zones where the settlements are located. In the summer season, farmers grow paddy, maize, vegetables, and in winter they grow vegetables, mustard and wheat. Agricultural production depends largely on seasonal rainfall. Paddy plantation begins after sufficient rainfall.

The northern part of the area is called bhadkhalo, meaning lowland. Farmers plant paddy in summer and wheat in winter. Recently, migrants have started poultry farm based on leasehold. Like tar, agricultural production also relies on seasonal rainfall. Generally, they plant paddy from the third week of June to the first week of July due to low moisture. Harvesting is generally done 15 days earlier in both tar and bhadkhalo than in sim due to variations in the humidity of the ecological landscapes.

The study area is heterogeneous in caste and ethnic compositions. There are Chhetri, Thapa-Magar and Newar. The settlements are located in clusters. However, each caste and ethnic group has their own settlement separated by a small muddy path. People follow the multiple economic strategies such as farming, livestock management, business and service for their adaptation. Young males generally work outside the household and engage in other economic activities, and females and old males engage in farming and livestock management. During field observation, the researcher found men playing cards at local tea shop on national holidays whereas women worked in the farmland. rain-fed agriculture.

For Kirtipurian farmers, weather fluctuation is not a new phenomenon. Elder farmers can recall several climatic fluctuations that occurred in the past, including those of delayed, erratic and little precipitation over the last few years. They often referred to events that are associated with weather fluctuations. One farmer recalled a heavy snowfall in 1944/45. At that event, villagers removed the snow from their roofs. A farmer said the government fined those farmers who did not grow any crops, even lentils, in farming land during the drought of 1945 A.D. Another recalled the earlier arrival of cold days in $1957 \mathrm{AD}$ by recalling the unripe paddy event; and another remembered the event of borrowing paddy seeds from relatives during the drought of $1982 \mathrm{AD}$, which was the lowest average rainfall year in the Kathmandu valley over the last 40 years (see Figure 1). In this way, farmers recalled the extreme natural hazards that had occurred in their lives, which are the most common methods to discuss the change in weather or climate pattern (Roncoli 2006; Vedwan 2006). The meteorological data also show fluctuations in average rainfall in certain intervals of time in the Kathmandu valley over the 40 years period and it was seen to decrease since 2003, except in 2007 (see Figure 1).

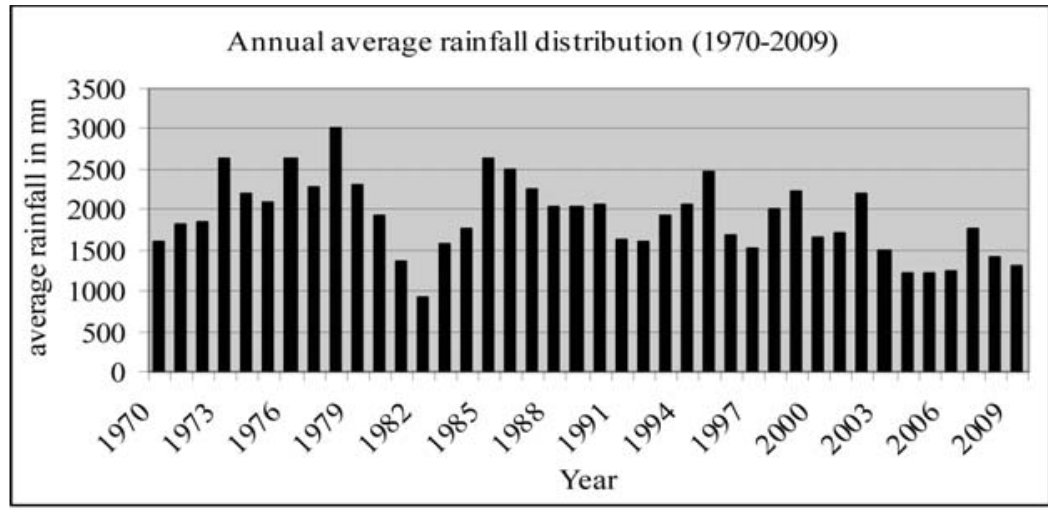

\section{Agriculture, Weather Fluctuations and Climate Change}

The agricultural calendar, everywhere in the world, may have developed based on seasons. Thus, farmers generally understand and interpret weather, seasons and climate by associating it with agriculture. The ongoing weather fluctuations and climate change have adversely threatened agricultural yields. Therefore, change in the weather patterns and climate can be understood in terms of cognized structure of crop-weather interaction (Vedwan and Rhoades 2001) rather than actual amount of rainfall (Roncoli, Crane and Orlove 2009). The researcher documented various indicators (precipitation, availability of water, temperature, dewfall) used by farmers to explain weather fluctuation and climate change by relating them to crops and agricultural activities. This paper focuses especially on precipitation for testing farmers' perception of climate variability due to the high dependence on

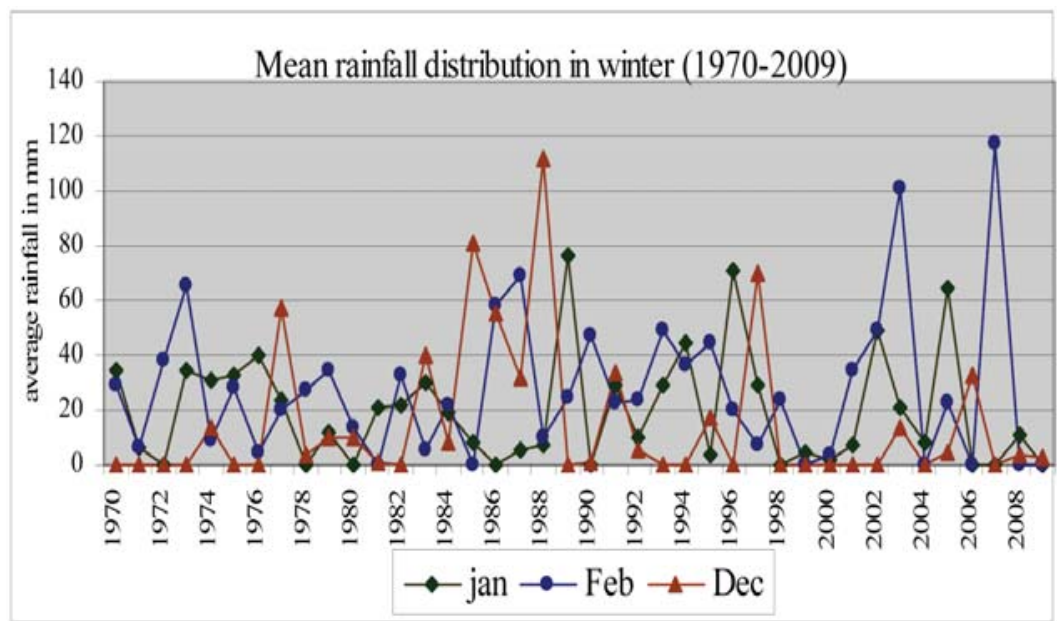

Figure 2. Average Rainfall Distribution in Winter (1970-2009). (Source: Department of Hydrology and Meteorology, Thankot Station)

Figure 1. Annual Average Rainfall Distribution of Thankot Station from 1970 to 2009. (Source: Department of Hydrology and Meteorology)

\section{Precipitation in the Past and the Present}

The farmers of Kirtipur reported that the timing and 
amounts of rainfall have been definitely changing over the last six years. Over a decade ago, winter rainfall would take place twice or thrice in a year. The first winter rainfall would occur in Push (mid-December to midJanuary), known as Puse-jhari. This rainfall would bring cold days in the Kathmandu valley. The second winter rainfall would take place during the beginning of Magh (midJanuary). It is called Maghe-jhari in the local language. It would remain for two to seven days. The cold days would spontaneously increase for a few days and then gradually begin to decrease and people would feel somewhat warm. The last winter rainfall would occur in Fagun (mid-February to midMarch), and cold days would end and the

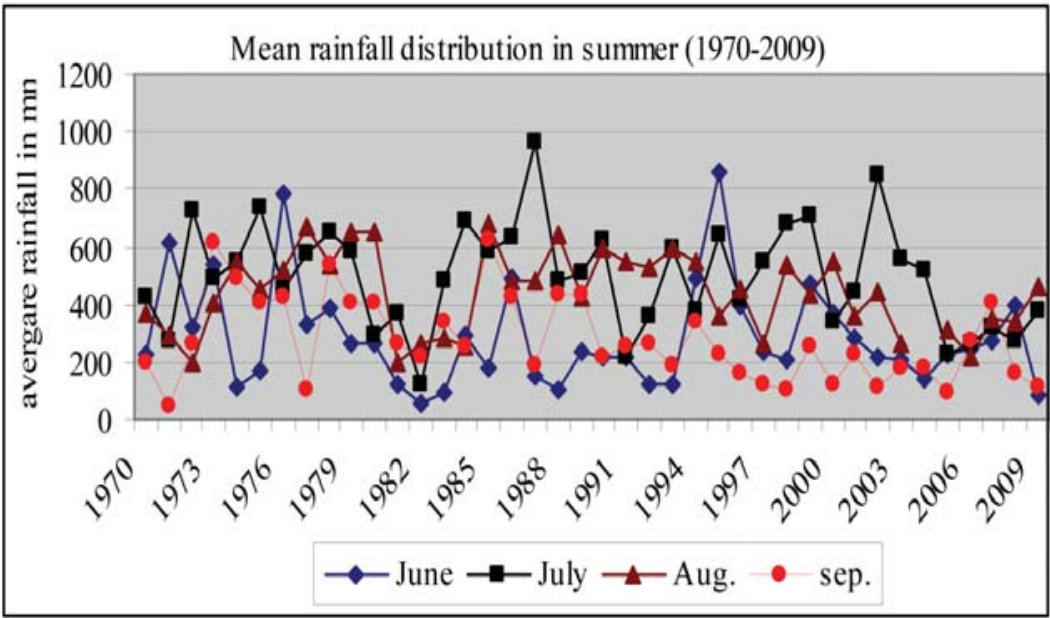
warm days began again. The meteorological data recorded from Thankot station also verifies the farmers' experiences about low rainfall over the last few years in the early days of winter months (see Figure 2).

For Kirtipurian farmers, winter rainfall was and is essential for growing winter crops like wheat, mustard, and vegetables. Since the last few years, farmers have been noticing little precipitation in winter, which has adversely affected winter crops like wheat and mustard. People were not able to grow wheat and mustard in less moist areas. In wetland, the production of wheat was dramatically reduced due to little rain or delayed precipitation. Farmers felt a shortage of green grasses to feed their cattle. Under such conditions, farmers were forced to purchase supplementary foods for human beings and cattle feed, which increased the economic burden on farmers.

Winter rainfall is not only essential to grow winter crops but it is also seen by locals as a sign about the nature of up-coming summer rainfall. In my field study, I frequently heard a statement from farmers that when the day of the winter rainfall (i.e., Maghe-jhari) occurs, the summer rainfall (Asare-jhari will come on the corresponding day. In this regard, an elderly Newar farmer (age 78) narrates his experiences about anticipation of rainfall and its uncertainty:

When I was child, the winter rainfall would occur in Magh and also on the same day in Asar. The amount of rainfall in Asar would be 1000 times greater than in the winter season. Today, there is no rainfall in Magh for the last five years. I cannot really tell what it is going to be. The precipitation in Asar and Saun is also erratic, the amount of rainfall is reducing and timing is being delayed. As a result, we could not plant wheat and paddy at the right time in winter and summer seasons respectively. Therefore, I cannot tell what is going to be like nowadays.

The experiences of elderly people reveal that the amount of rainfall has been decreasing sharply and the timing of rainfall has been shifting slightly from Asar (June/July) to Saun (July/August) compared to previous years. The meteorological data recorded from Thankot station also verifies the farmers' experiences about low, erratic, and shifting rainfall in summer months over the last few years in the Kathmandu valley (see Figure 3).

Figure 3. Average Rainfall Distribution in Summer (1970-2009). (Source: Department of Hydrology and Meteorology, Thankot Station)

Like winter crop plantation, summer rainfall is also essential to grow paddy. In a normal year, farmers broadcast paddy seed from the third to fourth weeks of May and transplant it within a month; i.e., before $15^{\text {th }}$ of Asar (3oth of June). Farmers reported that 22 to 30 day old seeds are "good" from the plantation viewpoint and more than that are "poor". Due to dependence on rain-fed agriculture, the timing of seeding transplantation relies on the duration; i.e., the timing and nature of the beginning of the rainy season. It is the key parameter through which they understand and evaluate precipitation. In other words, farmers categorized the duration of rain as "meaningful" or "meaningless" in terms of their observations of plant/ rain interaction, rather than by precipitation measure per se (Roncoli, Crane and Orlove 2009:190).

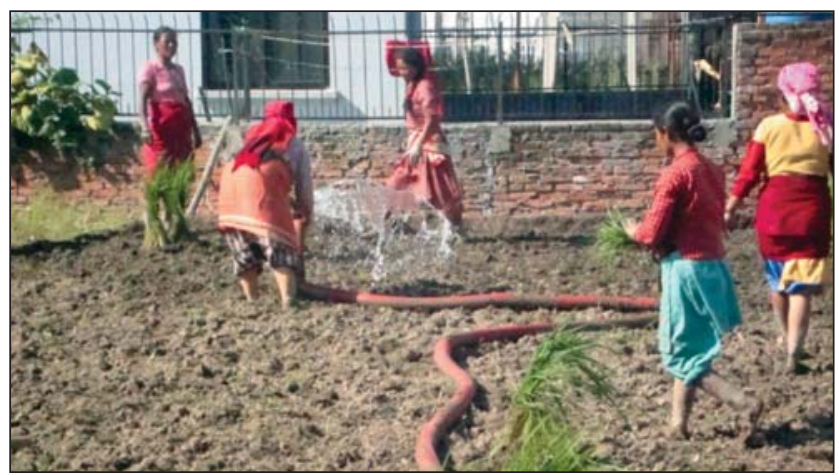

Figure 4. Using Water Tank for Watering in Paddy Field Due to Delay Onset of Rainfall in Summer.

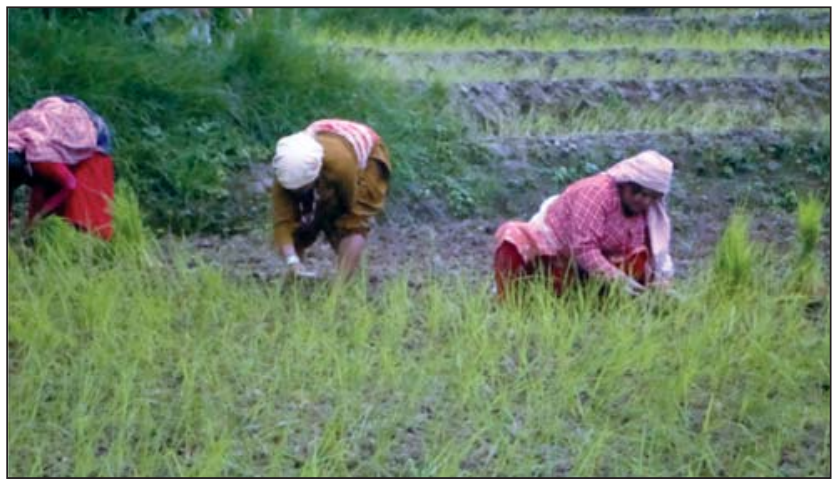

Figure 5. Maize as New Cropping Strategy in Low Precipitation in Summer. 
Over the last six years, farmers have been observing erratic, low and delay in rainfall, which continuously shift paddy plantation behind the normal time. During my field observation in 2010, some farmers were planting paddy on July 29 and seedlings were about two months old, which was poor from a plantation viewpoint. ${ }^{2}$ The plantation of poor seedling leads to delay in greenery and a high rate of dying of seedlings in the field, which reduces reproducing capacities of mother seedlings, increases bushes and small grasses, diseases, sprout and ripe unevenly, and reduces the quality and quantity of production, size of seeds, hay, etc. The untimely and low rainfall requires that farmers need to invest more labor for plantation, weeding, and protection of crops from harmful pests, and apply water from alternative ways like water tank (see Figure 4), well water for irrigation of the field for plantation, which in turn increases the cost. Similarly, some farmers planted maize due to low precipitation (see Figure 5).

A farmer narrated his experiences about the fluctuation of the rainfall situation in 2009:

Since the last five years, the rainfall has been erratic and shifting behind normal time. In 2009, some precipitation occurred in the beginning of summer; i.e., the third and fourth weeks of May. We prepared bed for paddy seeds and broadcasted it. After broadcasting, the seedlings were gradually growing up as a natural process. Rains did not fall about one and half month. Seedlings gradually began to die in the bed. To counter the drought, we (farmers) watered seedlings carrying water in buckets and pots.

These experiences clearly show that farmers cannot tell about actual quantity or static categories of rainfall as meteorologists do. The main parameter used by farmers to define rainfall and water deficit events is in terms of their observation of weather/plant interaction.

Similarly, some farmers in the study area reported that some canals, streams, springs and ponds were dried up; and some of them are in the state of disappearing due to little and erratic rainfall. A respondent said when asked about the condition of water sources:

Until about 15 years ago, we used canals for irrigation of the fields. There was enough water in the canals. Nobody would feel the shortage of water. We (farmers) would go to repair the canal in the last of Jestha (beginning of June). Before transplanting the (rice) paddy seedlings in the field, we used to store water in the paddy terrace for a few days to destroy the ground grasses and bushes, which also increased the nutrition of soil. At that time, there was a fixed date to transplant the paddy into the field. The source of water for the canal began to decrease about 15 years ago due to the growth of population and settlements near the mouth of the channel.

Ten years ago, the source of water for the canal completely dried up. Thereafter, we have depended on rainfall for transplanting our paddies. However, for the first five years after the water in the canal dried up, we could always plant the paddy on time due to consistent rainfall. For the last 5 years, however, God forgot to give water to us on time during the summer season. As a result,

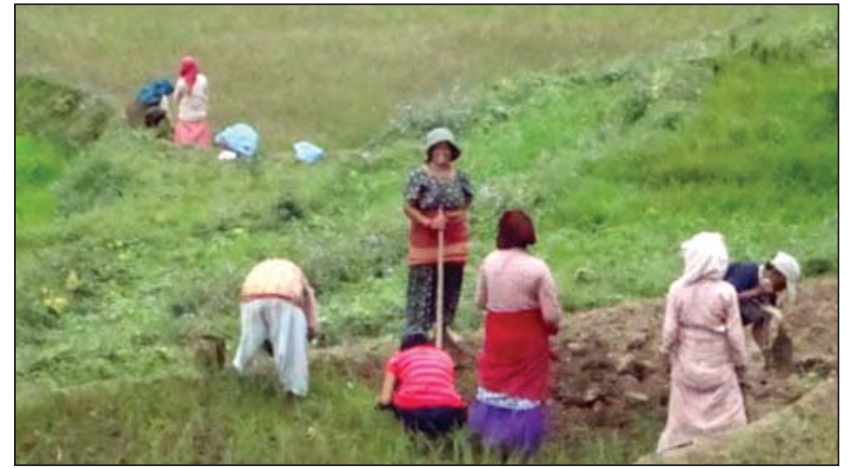

Figure 6. Farmers Transplanting Paddy Seedlings in Dry-Field.

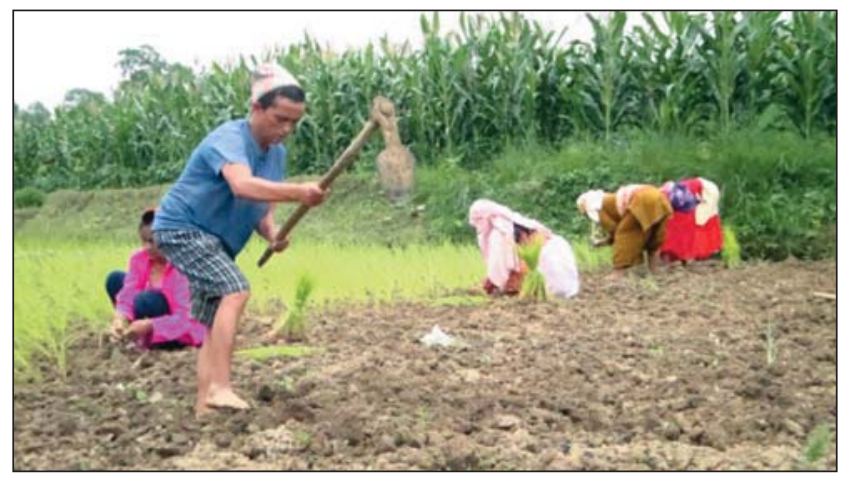

Figure 7. Planting Paddy Seedlings in Dry-Field.

we had to shift our paddy plantation period later than in the previous years. For instance, I planted paddy on June 15th in 2006. In 2007, it was done on June 2oth and in 2008 on June 23rd, each time without destroying ground grass and bushes. Last year in 2009 we planted paddy on June 29th and this year (2010) on July 1oth in a dry field, using small spades.

This is not a general statement about the dried up channels but it clearly shows the long term observational data that explain the change in the environmental aspects of particular geographical area over significant periods of time. Besides low and erratic rainfall, farmers also reported that population growth, road construction, new settlement, armed police camp settlement, set-up of dairy factory, etc., were equally responsible for the drying up of the spring and underground water that was/is the main source of their livelihood.

It was also found that farmers' perception of climatic variation does not rest on physical visibility alone but a cultural frame also plays a vital role for shaping their understanding. For instance, some farmers considered springs, streams and ponds as the living homes of many powerful gods and goddesses. They believe that benevolent behavior of human beings with gods and goddesses helps to maintain the equilibrium state of nature and nonbenevolent behavior leads to disequilibrium in nature including seasonality (low and erratic rainfall and drying up of water sources). In this regard, a woman (age 87) said "all taps of Machhenarayan dried up after having bath and washing clothes by a woman during her menstruation period." Similarly, an old man said "in 2003, a Brahmin priest put a flag printed with a Garud's (an eagle) picture while conducting the Purana in Toudaha, the living place of Karkotak Naag (snake). The Naag got angry and the rain stopped falling." Thus, different farmers define climate 
change differently, but a common notion among them is that climate has definitely changed in their surroundings over the last few years.

\section{Conclusions}

It is clear from the discussion above that climate change and weather fluctuations are not a new phenomenon in Kathmandu valley. Farmers have several eyewitness accounts about weather fluctuations which they have been monitoring in a lifetime. The data suggest, however, that farmers recall and understand climatic variability by weather/crop interaction, and events associated with climate and weather fluctuations; and their perceptions are shaped by both physical visibility (declining and disappearing of available resources, appearance of new plants and insects) and cultural frame (wrath of gods/ goddesses). This supports the ideas that farmers have a wide and varied knowledge about climatic variability in the local context. This, of course, does not mean that meteorological data are not useful, but the observed reality suggests that local systems are found more meaningful, subjective and contextual to interpret the climate variability in local context than by using other methods. Thus, it suggests that linkage between two knowledge systems is more salient for better understanding of climatic variability in the given context.

As noted in the text, farmers have been experiencing and observing low, erratic rainfall since 2003. The beginning of summer rainfall (Asare-jhari) has been gradually shifting behind. There was no or little rainfall in winter. It has negative consequences for agriculture; i.e., it becomes difficult to conduct paddy plantation in summer and wheat, mustard and vegetables in winter, thus leading to the loss of the quantity and quality of products and increase in economic burden to poor farmers.

At present, the climatic variability and changes have become more crucial in agriculture research and planning. Thus, climatic factors need to be included in any program which aims at maintaining and enhancing the agricultural sustainability of the Himalayan region (Vedwan and Rhoades 2001). In order to understand how people respond to climate change, it is essential to study people's perception of climatic variability in general. Therefore, farmers' knowledge should be incorporated in decision making processes while making strategies to mitigate the impacts of climate change. Moreover, any decision must be based on the concept of inclusion than exclusion as well as locally grounded knowing, seeing and valuing the world (Chhetri 2008; Roncoli, Crane and Orlove 2009). In this context, social scientists need to bridge scientific and local discourses about climatic variability.

\section{Acknowledgements}

I would like to thank the farmers of Kirtipur, especially Lekhaman Singh Khatri, for their kind cooperation during the field study, Prof. Dr. Ram Bahadur Chhetri for providing disciplinary suggestions, and Prof. Dr. Tej Ratna Kansakar for reading the paper.

Jiban Mani Poudel is a lecturer of Anthropology at Central Department of Sociology/Anthropology and currently enrolled in the PhD program in Anthropology at Tribhuvan University. He has conducted ethnographic research on topics related to socio-cultural issues in natural resources, and adaptive strategies. The results of his work have been published in various academic journals and books including Occasional Papers in Sociology/Anthropology, Journal of SASON, and Social Sciences in a Multicultural World. His current work focuses on human dimensions on weather, climate and seasons, especially peoples' experiences, perceptions, impacts and adaptation. He has written some articles on the same issues entitled Oral Tradition in Weather and Climate Research and Reading the Rains: Local Knowledge on Weather Forecasting System. Corresponding address:jm_poudel@yahoo.com

\section{Notes}

1 Kenneth Broad and Ben Orlove (2007) studied the 1997-98 El Niño climate event of Peru.

2 According to DHM records from Thankot station, it was the highest rainfall day in 2009.

\section{References}

Broad, K. and B. Orlove, 2007, 'Channeling globality: The 1997-98 El Nino climate events in Peru', American Ethnologist 34(2):265-302

Chhetri, R.B., 2008, "Culturally Embedded Knowledge in Irrigation: People's Ways of Thriving in a Himalayan Village”, pp.135-154 in H.R. Ojha, N. Timsina, R.B. Chhetri and K.P. Paudel (eds.), Knowledge Systems and Natural Resources: Management, Policy and Institutions in Nepal, New Delhi: Cambridge University Press.

Crate, S A., 2008, 'Gone the bull of winter?: Grappling with the cultural implications of and anthropology's role(s) in global climate change', Current Anthropology 49(4):569-595.

Kempton, W., J.S. Boaster and J. Hartley, 1997, Environmental Values in American Culture, Cambridge, MA: MIT press.

Orlove, B., E. Wiegandt and B. Luckman, 2008, 'The place of glaciers in natural and cultural landscapes: Environment, history and culture as influences on perceptions of glacier dynamics', pp.3-19 in B. Orlove, E. Wiegandt and B. Luckman (eds.), Darkening Peaks: Mountain Glaciers Retreat Social and Biological Context, Berkeley and Los Angeles: University of California Press.

Rappaport, R., 1979, Ecology, Meaning and Religion, Berkeley, CA: North Atlantic Books.

Roncoli, C., 2006, 'Ethnography and participatory approaches to research on farmers' responses to climate predictions', Climate Research 33:81-99.

Roncoli, C., T. Crane and B. Orlove, 2009, 'Fielding climate change in cultural anthropology', pp. 87-115 in S. Crate and M. Nuttall (eds.), Anthropology and Climate Change: From Encounter to Action, Walnut Creek, CA: Left Coast Press.

Vedwan, N., 2006, 'Culture, climate and the environment: Local knowledge and perception of climate change among apple growers in northwestern India', Journal of Ecological Anthropology 10:4-18.

Vedwan, N. and R.E. Rhoades, 2001, 'Climate change in the western Himalayas of India: A study of local perception and response', Climate Research 19:109-117.

West, C.T. and M. Vásquez-León, 2003, 'Testing farmers' perceptions of climate variability: A case study from the Sulphur Springs Valley, Arizona', pp. 233-250 in S. Strauss and B. Orlove (eds.), Weather, Climate and Culture, Oxford: Berg.

Strauss, S. and B. Orlove, 2003, 'Upintheair: The anthropology of weather and climate', pp. 3-24 in S. Strauss and B. Orlove (eds.), Weather, Climate and Culture, Oxford: Berg. 